\title{
MÉTODOS PARA A CLIMATIZAÇÃO DE BANANAS 'PRATA-ANÃ' PRODUZIDAS NA AMAZÔNIA SETENTRIONAL BRASILEIRA ${ }^{1}$
}

\author{
MARCOS ANDRÉ DE SOUZA PRILL², LEANDRO CAMARGO NEVES 3 , \\ EDVAN ALVES CHAGAS ${ }^{4}$, JESSICA MILANEZ TOSIN ${ }^{5}$, SAMUEL SILVA SILVA ${ }^{5}$
}

RESUMO-O objetivo, neste trabalho, foi avaliar o uso da climatização para a uniformização de bananas 'Prata-Anã' produzidas em Boa Vista-RR. Após colhidos, os frutos foram selecionados no formato de buquês, sanitizados, climatizados por abafamento com lona plástica ou por imersão em solução de Ethrel®, embalados com filme de polietileno de baixa densidade e armazenados por quatro períodos de tempo ( 0 ; $10 ; 20$ e 30 dias) a $12 \pm 1{ }^{\circ} \mathrm{C}$ e $93 \pm 2 \%$ de UR. Após cada período de armazenamento refrigerado (AR) os frutos foram submetidos ao armazenamento em condições ambiente $\left(22 \pm 1^{\circ} \mathrm{C}\right.$ e $\left.75 \pm 3 \% \mathrm{UR}\right)$, retirados das embalagens plásticas e sendo analisados após 1;2; 3 e 4 dias. As seguintes análises foram realizadas: perda de massa fresca, coloração da casca, produção de etileno e $\mathrm{CO}_{2}$, atividade das enzimas pectinametilesterase e poligalacturonase, acidez titulável (AT), pectina total e solúvel, amido e sólidos solúveis (SS). Não houve diferenças significativas entre os métodos de climatização, porém verificou-se que, quanto maior o período de AR e de condicionamento, menor foi o período de conservação das bananas 'Prata-Anã'. Ficou evidenciado, também, que a climatização, independentemente do método utilizado, deve ser realizada em até 20 dias após a colheita, nas condições de AR aqui testadas. Nessas condições, foi possível manter a qualidade sensorial das bananas por até 3 dias após a retirada dos frutos do armazenamento refrigerado.

Termos de indexação: Armazenamento refrigerado, climatização, Musa sp., pós-colheita.

\section{METHODS OF CLIMATIZATION OF 'PRATA-ANÃ' BANANAS CULTIVATED IN THE NORTHERN BRAZILIAN AMAZON}

\begin{abstract}
The aim of this study was to evaluate the use of climatization on standardization of 'Prata-Anã' bananas cultivated in Boa Vista, Roraima. After harvested, fruits were selected in the shape of bouquets, sanitized, conditioned by muffling with plastic sheeting or by immersion in a Ethrel ${ }^{\circledR}$ solution, packed with low density polyethylene and stored for four time periods $(0,10,20$ and 30 days $)$ at $12 \pm 1{ }^{\circ} \mathrm{C}$ and $93 \pm 2 \%$ RH. After each period of cold storage (CS), the fruits were taken out of refrigerator and submitted to the ambient condition $\left(22 \pm 1{ }^{\circ} \mathrm{C}\right.$ and $75 \pm 3 \%$ R.H. $)$, removed from the plastic bags and analyzed after 1, 2, 3 and 4 days after each period of cold storage. The following analysis were performed: loss of fresh weight, peel color, $\mathrm{CO}_{2}$ /ethylene production inside the bags, enzymatic activity of polygalacturonase (PG) and of pectin methyl esterase (PE), titratable acidity (TA), total and soluble pectin content, starch content and soluble solids (SS). There were no significant differences between the methods of climatization, but it was found that as longer the period of cold storage and climatization, as lower was the shelf-life of the 'Prata-Anã' bananas. It was also shown that climatization, regardless of the method applied, must be held within 20 days after harvest, when the fruits are submitted to the CS conditions here tested. In these conditions, it was possible to maintain sensory quality of bananas for at least 3 days after removal the fruits from the cold storage.
\end{abstract}

Index terms: Cold storage, conditioning air, Musa sp., postharvest.

\footnotetext{
${ }^{1}$ (Trabalho 090-12). Recebido em: 08-02-2012. Aceito para publicação em: 30-07-2012.

${ }^{2}$ Mestre em Agronomia (POSAGRO/UFRR), Universidade Federal de Roraima, Boa Vista-RR. Email: marcosprill@bol.com.br ${ }^{3}$ Prof., Pós-Doutor in Food Science, Dept ${ }^{\circ}$ de Fitotecnia da Universidade Federal de Roraima (DFT/UFRR), 69310-270, Boa Vista-RR.Email: rapelbtu@hotmail.com

${ }^{4}$ Pesquisador Embrapa/Roraima, Dr. em Fruticultura, Boa Vista-RR. Bolsista de Produtividade em Pesquisa do CNPq. Email: edvan. chagas@embrapa.br

${ }^{5}$ Graduandos em Agronomia da Universidade Federal de Roraima, Boa Vista-RR. Emails: jessica.mtosin@hotmail.com; samuel.eng.agr@gmail.com
} 


\section{INTRODUÇÃO}

Em 2008, o Brasil produziu quase 7 milhões de toneladas de banana (FAO, 2011), sendo a região Nordeste a maior produtora (34\%), seguida das regiões Norte (26\%), Sudeste (24\%), Sul (10\%) e Centro-Oeste (6\%) (ALVES et al., 2007).

Em Roraima, a bananicultura está presente em todos os municípios, com maior expressão na região de Campos Novos e no sul do Estado (MOREIRA et al., 2007). A produção roraimense abastece $75 \%$ e $55 \%$ dos mercados de Boa Vista-RR e Manaus-AM, respectivamente (MOREIRA et al., 2007). O principal problema da bananicultura roraimense consiste no manejo do produto a partir da colheita, envolvendo o transporte, embalagem, climatização, manuseio e logística do mercado consumidor. Segundo Lichtemberg et al. (2001), a falta de cuidados durante a pós-colheita é também responsável pela desvalorização da banana no mercado interno e pela perda de oportunidades para a exportação do fruto.

De acordo com Kader (2002) e Neves (2009), para suprir as demandas do mercado, os frutos climatéricos, como a banana, devem ser colhidos na maturidade fisiológica. Porém, a banana colhida com completo desenvolvimento fisiológico amadurece de forma desuniforme. Visando à homogeneização dos lotes e ao amadurecimento programado dos frutos, pode-se utilizar o processo de climatização (BOTREL et al., 2003). No entanto, não há para todas as cultivares de banana conhecimento em relação ao efeito sobre a qualidade, do tempo entre a colheita e a climatização (SILVA et al., 2006), principalmente a respeito de cultivares produzidas na Amazônia.

A banana produz elevados níveis de etileno durante o amadurecimento. Portanto, considerando-se que a qualidade está relacionada à minimização da deterioração, ou seja, à manutenção das características sensoriais do produto, faz-se necessário utilizar tecnologias que não acelerem demasiadamente-a maturação (ROCHA, 2005). Campos et al. (2003) afirmaram que vários fatores devem ser controlados durante o processo de climatização, dentre os quais a temperatura, a umidade relativa, o gás ativador, a composição atmosférica, a circulação de ar e a exaustão, visando a melhorar a uniformização do grau de amadurecimento dos frutos para a comercialização.

Tradicionalmente, a climatização da banana é realizada utilizando-se de carbureto de cálcio, que, umedecido, libera acetileno no ambiente que contém as pencas (MEDINA, 2004). O acetileno é análogo ao etileno e pode ocasionar efeito fisiológico similar nos tecidos vegetais (BISOGNIN et al., 2007). Outra alternativa é o uso de ethephon (ácido 2-cloroetilfosfônico), que libera etileno exógeno e aumenta a intensidade e antecipa o pico respiratório das bananas, durante o amadurecimento (NOGUEIRA et al., 2007).

O objetivo deste trabalho foi avaliar métodos de climatização, associados a diferentes tempos de AR, em bananas 'Prata-Anã' produzidas em Boa Vista-RR, visando à uniformidade e à padronização das mesmas.

\section{MATERIAL E MÉTODOS}

$\mathrm{O}$ experimento foi realizado com frutos de bananeira 'Prata-Anã' no período de janeiro a fevereiro de 2010, colhidos na empresa Roraima Agrofrutas (latitude $2^{\circ} 50^{\prime} 06^{\prime \prime} \mathrm{N}$ e longitude $60^{\circ} 40^{\prime} 28^{\prime \prime}$ W). O ponto de colheita foi definido observando-se parâmetros visuais das frutas, considerando-se sua redução na angulosidade, a coloração no estádio 1 (CEAGESP, 2006), bem como por amostragem, que indicou quando os frutos apresentavam teores médios de sólidos solúveis de $3,6^{\circ}$ Brix e acidez titulável de $2,32 \%$ de ácido málico $100 \mathrm{~g}^{-1}$ de polpa.

Os cachos colhidos foram transportados para a casa de embalagem da empresa Roraima Agrofrutas, onde passaram por pré-limpeza e eliminação da ráquis. Em seguida, foram resfriadas por imersão em tanque com água, sulfato de alumínio e cloreto de cálcio a $2 \%$, a $20 \pm 2{ }^{\circ} \mathrm{C}$, por 20 minutos, seguido da divisão em buquês. Os frutos foram então transportados em caixas plásticas de $20 \mathrm{~kg}$ até o Laboratório, onde foram imersos em solução de hipoclorito de sódio a $2,5 \%$, por 10 minutos. O enxágue e a secagem foram realizados ao $\operatorname{ar}\left(22 \pm 1{ }^{\circ} \mathrm{C}\right.$ e $75 \pm 3 \%$ UR $)$, por 30 minutos.

Os buquês, com 3 a 5 dedos, depois de selecionados e padronizados quanto ao tamanho e ausência de danos/defeitos visuais, receberam os seguintes tratamentos: T1-Abafamento realizado na colheita;T2-Ethrel ${ }^{\circledR}$ aplicado na colheita;3-Abafamento realizado após 10 dias de AR; T4-Ethrel ${ }^{\circledR}$ aplicado após 10 dias de AR; T5-Abafamento realizado após 20 dias de AR; T6-Ethrel ${ }^{\circledR}$ aplicado após 20 dias de AR; T7-Abafamento realizado após 30 dias de AR; T8-Ethrel ${ }^{\circledR}$ aplicado após 30 dias de AR.

Após a aplicação dos tratamentos, os buquês acondicionados em embalagens de polietileno de baixa densidade (PEBD) foram armazenados em câmara frigorífica a $12 \pm 1{ }^{\circ} \mathrm{C}$ e $93 \pm 2 \%$ UR, por até 30 dias. O filme de polietileno de baixa densidade (PEBD) tinha $0,010 \mathrm{~mm}$ de espessura, área de permeabilidade de $805 \mathrm{~cm}^{3}$, permeabilidade ao oxigênio $\left(\mathrm{TPO}_{2}\right)$ de $11.234 \mathrm{~cm}^{3} \mathrm{~m}^{-2} \mathrm{~d}^{-1}$ e permeabilidade ao gás carbônico $\left(\mathrm{TPCO}_{2}\right.$ ) de $36.705 \mathrm{~cm}^{3} \mathrm{~m}^{-2} \mathrm{~d}^{-1}$. Em cada embalagem, 
foi aplicado vácuo de $160 \mathrm{mmHg}$ ) e adicionado um sachê adsorvedor de etileno da marca Always Fresh ${ }^{\circledR}$, da Soloeste.

Após cada período de $\mathrm{AR}$, os frutos foram levados a condição de ambiente $\left(22 \pm 1{ }^{\circ} \mathrm{C}\right.$ e $75 \pm 3 \%$ UR), 12 horas antes de serem submetidos à climatização, para a elevação da temperatura dos frutos até o equilíbrio com a do ambiente.

Após a retirada das embalagens, os frutos foram climatizados, usando-se o ácido 2-cloroetilfosfônico ou etephon (Ethrel®). Os buquês foram imersos, por 10 minutos, em solução com $166 \mathrm{~mL}$ do produto comercial, em $100 \mathrm{~L}$ de água. No tratamento com abafamento, os frutos foram envoltos em lona plástica (polietileno com fio de ráfia interno), marca Lona Leve, tipo caminhoneiro. Após $12 \mathrm{~h}$ de climatização, os frutos foram levados a condição de ambiente $\left(22 \pm 1{ }^{\circ} \mathrm{C}\right.$ e $75 \pm 3 \%$ UR), quando foram analisados, diariamente e por 4 dias, quanto:

Perda de massa fresca, quantificada pela variação percentual (\%) da massa fresca de cada buquê, em relação a sua massa fresca inicial. Coloração da casca, avaliada utilizando-se a escala subjetiva de valores proposta por Von Loesecke, em 1950 (CEAGESP, 2006).

A concentração de etileno foi quantificada por cromatografia gasosa, utilizando cromatógrafo a gás marca Varian $\AA$, modelo 3300 , equipado com coluna de aço inox 1/8", preparado com Porapak ${ }^{\circledR} \mathrm{N}$ e detector de ionização de chama. A concentração de $\mathrm{CO}_{2}$ foi quantificada em cromatógrafo Shimadzu ${ }^{\circledR}$ CR 950, equipado com sistema de detecção por condutividade térmica. Foram utilizados como padrões misturas gasosas contendo etileno a $100 \mathrm{mg} \mathrm{kg}^{-1} \mathrm{e}$ $\mathrm{CO}_{2}$ a $5 \%$. Os resultados foram expressos em $\mu \mathrm{L}$ de etileno $\mathrm{kg}^{-1} \mathrm{~h}^{-1}$ e mg de $\mathrm{CO}_{2} \mathrm{~kg}^{-1} \mathrm{~h}^{-1}$.

A atividade da enzima pectinametilesterase (PME) foi determinada segundo Jen e Robinson (1984), avaliando-se sua capacidade de catalisar a desmetilação da pectina, com os resultados expressos em $\mu \mathrm{mol}$ de $\mathrm{NaOH} \mathrm{g}{ }^{-1} \mathrm{~min}^{-1}$. A atividade da enzima poligalacturonase $(\mathrm{PG})$ foi determinada segundo Pressey e Avants (1973), onde se avaliou a capacidade da enzima em catalisar a formação de 1 ๆmol de açúcar redutor, por minuto, por grama de amostra.

Os teores de acidez titulável (AT) foram determinados pela titulação de $10 \mathrm{~g}$ de polpa triturada, homogeneizada e diluída para $100 \mathrm{~mL}$ em água destilada, com solução de $\mathrm{NaOH}$ a $0,1 \mathrm{M}$, e ponto de viragem no $\mathrm{pH} 8,2$. Os resultados foram expressos em $\%$ de ácido málico $100 \mathrm{~g}^{-1}$ de polpa (IAL, 2008). Os de pectina total e solúvel, extraídas segundo McCready e McCoomb (1952) e determinadas colorimetricamente pela reação com carbazol, segundo Bitter e Muir (1962), foram expressos em porcentagem (\%) de ácido galacturônico $100 \mathrm{~g}^{-1}$ de polpa.

$\mathrm{O}$ teor de amido foi determinado em $1 \mathrm{~g}$ de amostra, previamente seca, em que se adicionaram $50 \mathrm{~mL}$ de $\mathrm{HCl}$ a $1 \mathrm{M} \mathrm{e}$, em seguida, foram tratados em micro-ondas durante 20 minutos, em potência máxima, para a hidrólise do amido. A seguir, a amostra foi neutralizada com $\mathrm{NaOH}$ a $10 \%$, tendo-se fenolftaleína como indicador, até a coloração rósea, com os resultados expressos em mg de glicose 100 $\mathrm{g}^{-1}$ de polpa. O teor de sólidos solúveis (SS) foi determinado por refratometria, em refratômetro portátil, modelo - RT 30ATC, com os resultados expressos em ${ }^{\circ}$ Brix (IAL, 2008).

$\mathrm{O}$ experimento foi conduzido em delineamento inteiramente casualizado (DIC), com o esquema fatorial $2 \times 4$ (climatizações $\mathrm{x}$ dias de análises), com 3 repetições, sendo cada repetição composta por 2 buquês. Feita a análise exploratória dos dados, constatou-se que os mesmos seguiam distribuição normal, os erros eram independentes e apresentavam homocedasticidade. Assim, os dados foram submetidos à análise de variância pelo teste F, e a comparação de médias efetuada pelo teste de Tukey, a $5 \%$ de probabilidade estatística.

\section{RESULTADOS E DISCUSSÃO}

Detectaram-se diferenças significativas nas perdas de massa fresca entre os frutos submetidos a diferentes períodos de AR (Figura 1) e entre os dias após a climatização, com aumentos progressivos e estatisticamente diferentes entre os períodos de climatização.

Considerando-se o valor aceitável da perda de massa fresca entre 5 e 10\% (KADER, 2002), verificou-se que os frutos climatizados logo após a colheita se mantiveram praticamente turgidos e com perdas de massa fresca não prejudiciais do ponto de vista qualitativo até o $4^{\circ}$ dia após o processo de climatização. Contudo, os frutos climatizados após 30 dias de AR estavam no limite da tolerância do intervalo sugerido por Kader (2002), devendo ser imediatamente encaminhados à comercialização.

Os frutos climatizados após 10 e 20 dias de AR sempre apresentaram perdas de massa fresca inferiores aos limites citados anteriormente por Kader (2002) . Nesse sentido, Silva et al. (2006), avaliando a pós-colheita de bananas 'Prata' por período de 5 dias de $\mathrm{AR}$, e climatizadas no $1^{\circ}, 2^{\circ}$ e $3^{\circ}$ dias após a colheita, observaram perdas de massa fresca significativas já no $1^{\circ}$ dia de avaliação, sendo que os frutos climatizados tardiamente apresentaram as maiores perdas de massa fresca, assim como verificado aqui nos frutos climatizados após 30 dias de AR. Segundo Silva et al. (2006), decorridos 3 dias após a colheita e 
posterior climatização, os valores entre os tratamentos foram estatisticamente semelhantes; contudo, segundo esses mesmos autores, evidentemente fora dos padrões de comercialização e consumo.

Foi verificado também, aos 20 dias de AR, desde o primeiro dia após aplicação do Ethrel ${ }^{\circledR}$ ou da realização do abafamento nos frutos, diferença significativa entre os tratamentos testados. Contudo, a perda de massa fresca dos frutos nos dias subsequentes à climatização pode ser atribuída à condição de estresse causada a partir da saída do AR, assim como pela retirada dos frutos das embalagens de PEBD contendo o sachê adsorvedor de etileno. Assim, por tratar-se de um tecido vegetal vivo, as bananas 'Prata-Anã' apresentaram processo natural de amadurecimento, sendo por sua vez retardado pelo uso do sachê adsorvedor (NEVES et al., 2008) e/ou acelerado pela aplicação do etileno exógeno.

Neste experimento, observou-se que quanto maior o período sob refrigeração, maior foram as perdas de massa fresca. Após a climatização, os frutos apresentaram as maiores perdas de massa no $3^{\circ}$ e $4^{\circ}$ dias, dependendo do tempo de AR. A perda de massa fresca pelos frutos indicou que a climatização seja realizada em frutos armazenados por até 20 dias após a colheita, a $22 \pm 1^{\circ} \mathrm{C}$ com 3 dias, em média, para a comercialização.

Não houve diferença significativa entre os tratamentos Ethrel ${ }^{\circledR}$ e abafamento na coloração da casca (Figura 2). A diferença significativa observada entre ambos, após 20 dias de AR e 2 dias após a climatização, foi atribuída a diferenças naturais entre a maturação dos frutos.

Os frutos climatizados após 30 dias de AR alcançaram coloração adequada no primeiro dia após a climatização, quando, a partir daí, perderam rapidamente a qualidade, pelo acelerado comportamento respiratório (Figuras $3 \mathrm{a}$ e $3 \mathrm{~b}$ ) e atividade enzimática (Figuras 5a e 5b). Por outro lado, os frutos climatizados após 20 dias de refrigeração tinham coloração adequada entre o $2^{\circ}$ e $03^{\circ}$ dias após a climatização, levando em consideração os padrões de coloração citados por Matsuura (2004). Já os frutos climatizados no dia da colheita só atingiram coloração aceitável a partir do terceiro dia após a climatização. Nesse contexto, Manoel (2008) indicou que o melhor período para aplicação de etileno nas bananas 'Nanica' irradiadas, sem o comprometimento da qualidade sensorial dos frutos, foi entre 24 e 48 horas após a colheita. No entanto, segundo os resultados aqui apresentados, constatou-se que o período seguro para que ocorra a climatização de bananas 'Prata-Anã', com adequada manutenção dos atributos de qualidade, tal como a própria coloração das bananas, seja de até 20 dias, desde que realizado o AR nas condições aqui descritas.

Na Figura 3, a são apresentadas as épocas após a climatização onde se detectou o pico de produção de etileno, cuja maior produção acelerou o amadurecimento dos frutos. Por outro lado, mesmo com a aplicação exógena de etileno, verificou-se que as bananas climatizadas após 30 dias de refrigeração não apresentaram pico de produção de etileno. Acredita-se que esse pico deva ter ocorrido antes do $1^{\circ}$ período de análise, dado o acelerado metabolismo destes frutos.

Os frutos climatizados após 20 dias de refrigeração apresentaram o pico de etileno no $1^{\circ}$ dia após a climatização, enquanto os amadurecidos após 10 dias de refrigeração ou logo após a colheita apresentaram picos no $2^{\circ}$ e $3^{\circ}$ dias após a climatização, respectivamente. Após o pico de produção de etileno, os frutos de todos os tratamentos apresentaram redução na produção de etileno, típica de frutos climatéricos (NOGUEIRA et al., 2007; NEVES et al., 2009).

Quanto à respiração, o clímax ocorreu em diferentes datas após a climatização, seguido de drástica redução em todos os frutos, o que caracterizou o estádio de senescência (SILVA et al., 2006). Assim, nos frutos climatizados logo após a colheita, o aumento na taxa respiratória teve seu ponto de máximo no $4^{\circ}$ dia após a climatização, inviabilizando a comercialização dos mesmos em polos mais distantes. Nos frutos climatizados após 30 dias de refrigeração, a produção de $\mathrm{CO}_{2}$ reduziu-se de maneira constante e gradativa, do $1^{\circ}$ até o $4^{\circ}$ dia após a climatização, claramente caracterizando esses frutos como senescentes. Para os frutos climatizados aos 10 e 20 dias, o pico de produção de etileno e de $\mathrm{CO}_{2}$ foram retardados pelos tratamentos empregados. Nesse sentido, Nogueira et al. (2007), climatizando bananas 'Nanica' e 'Pacovan', também verificaram que após o pico climatério, a produção de $\mathrm{CO}_{2}$ pelos frutos declinou. Isso aconteceu, provavelmente, devido ao decréscimo de substratos energéticos usados na respiração, utilizados para a produção da energia necessária aos processos moleculares e fisiológicos referentes ao amadurecimento.

Com o amadurecimento, a acidez titulável das bananas aumentou (Figura 4), com incrementos relativamente constantes, o que pode ser efeito da solubilização de substâncias pécticas como consequência da atividade enzimática (Figuras 5a e 5b).

No final do período de avaliação, foram detectadas reduções nos teores de AT dos frutos climatizados após 30 dias de AR, o que é devido ao estádio de senescência desses frutos, assim como afirmado por Melo e Vilas Boas (2007). Acredita-se também que os frutos climatizados na colheita e aos 10 e 20 dias de AR também apresentariam o mesmo comportamento. Entretanto, justamente devido às diferenças no estádio de maturidade desses frutos, não se observaram tais reduções durante o período de avaliação.

As atividades da PME e PG apresentaram 
comportamento semelhante (Figuras 5a e 5b), não sendo observaram o mesmo comportamento relatado por Melo e Vilas Boas (2007). No presente trabalho, verificou-se que, de modo geral, a atividade enzimática apresentou 2 picos de atividade, sendo que, para os frutos climatizados aos 30 dias de AR, o $1^{\circ}$ e o $2^{\circ}$ pontos de máximo ocorreram no $1^{\circ}$ e $3^{\circ}$ dias após a climatização, respectivamente. Para os frutos climatizados aos 20 dias de AR, aconteceram aos 2 e 4 dias da climatização, respectivamente. No entanto, os frutos climatizados aos 10 dias de AR e na colheita somente apresentaram um pico de atividade enzimática, justamente ocorrido aos 3 e 4 dias após a climatização, respectivamente. Nesse caso, não houve tempo experimental para a visualização do $2^{\circ}$ ponto de máxima atividade, que supostamente poderia ocorrer depois do $4^{\circ}$ dia subsequente à climatização. Esses picos de atividade enzimática foram concomitantes tanto para PME como para a PG, muito embora Melo e Vilas Boas (2007) tenham observado algumas diferenças temporais, em que a ação da PME antecedeu a ação enzimática da PG. Acredita-se, segundo os resultados aqui apresentados, que os efeitos sinérgicos dessas 2 enzimas apresentaram importante papel no processo de desmetilação das pectinas (Figuras 6a e 6b). Os resultados encontrados indicam que a atividade dessas enzimas atuou no amadurecimento dos frutos de banana, porém essa atuação aconteceu com velocidades distintas, dados os diferentes estádios de maturação em que os frutos se encontravam dentro de cada tratamento.

Observou-se redução nos teores de pectina total durante o período sob refrigeração (Figura 6a), sendo a velocidade e a intensidade dessas transformações influenciadas pelos tratamentos realizados, o que também foi constatado por Melo e Vilas Boas (2007). O AR,associado ao uso do sachê adsorvedor de etileno, apenas retardou o amadurecimento dos frutos. Quanto maior o período de AR, maiores também foram as reduções significativas no conteúdo de pectina total entre tratamentos nos dias subsequentes à climatização. Isso também indica a ocorrência de diferentes estádios de maturação entre os frutos, devido aos tratamentos realizados.

A solubilização da pectina (Figura $6 b$ ) foi responsável pelo amaciamento da polpa, que ocorre naturalmente durante o amadurecimento dos frutos (MELO; VILAS BOAS, 2007). Isto indica que as modificações na textura das bananas ocorreram em decorrência da solubilização das pectinas, por ação da $\mathrm{PG}$, com incrementos significativos próximos ao pico climatérico, e o correspondente aumento nos teores de pectina solúvel (SALES et al., 2004).

Nesse contexto, os frutos climatizados após 30 dias de refrigeração apresentaram as maiores reduções nos teores de pectina total, tanto no início quanto ao final do período, enquanto as menores reduções foram observadas nos frutos climatizados no dia da colheita. A maior e mais rápida solubilização das pectinas aconteceram nos frutos climatizados após 30 dias sob refrigeração, logo no $1^{\circ}$ dia após este tratamento, seguido de redução. Os frutos climatizados após 20 dias de refrigeração apresentaram aumento até o $3^{\circ}$ dia, com posterior redução nos teores de pectina solúvel. Quanto maior foi o período de AR, menor foi o período após a climatização para que os frutos alcançassem as características sensoriais ideais.

Ocorreram reduções nos teores de amido nos frutos durante o AR e nos dias subsequentes às climatizações (Figura 7). Estas reduções são consideradas normais em bananas (MARTINS et al., 2007). e tiveram a intensidade diretamente relacionada com o grau de maturidade em que os frutos se encontravam, que foi influenciada pelos tratamentos propostos, indicando que, durante o período refrigerado, ocorreu amadurecimento dos frutos. As bananas amadurecidas após 30 dias de refrigeração apresentaram os menores teores de amido após a climatização. Nogueira et al. (2007) também verificaram que os teores de amido em bananas verdes diminuíram durante o amadurecimento sob refrigeração, pelo consumo de carboidratos no processo respiratório, com aumento nos teores de sólidos solúveis (Figura 8) e na acidez titulavel (Figura 3), conforme o relatado por Martins et al. (2007), que trabalharam com o efeito de diferentes pontos de colheita em bananas 'Prata-Anã'.

Não se observou diferença significativa nos teores de amido devido à ação do Ethrel ${ }^{\circledR}$ ou do abafamento, porém os frutos climatizados após o armazenamento por período maior apresentaram maior velocidade na degradação do amido, indicando sua maior suscetibilidade à ação do etileno. Assim como o observado para a perda de massa fresca (Figura 1), evolução da coloração (Figura 2) e variação na AT (Figura 4), observou-se que os teores de amido nos frutos submetidos ao AR por 20 dias estavam em maiores concentrações entre o $2^{\circ}$ e o $3^{\circ}$ dia após a climatização.

Não foram verificadas diferenças significativas entre os tratamentos Ethrel ${ }^{\circledR}$ e abafamento para os teores de SS (Figura 8), com aumentos nesses teores durante os períodos de refrigeração. Ao se determinar esses teores nos dias após os períodos de armazenamento testados, verificaram-se padrões distintos. Nos climatizados logo após a colheita, foram observadas constantes elevações nesses teores, com os maiores valores no $4^{\circ}$ dia. O mesmo foi observado para os frutos refrigerados por 10 dias, com exceção dos frutos submetidos ao tratamento com Ethrel ${ }^{\circledR}$. Constatou-se também que os frutos submetidos a 20 dias de $\mathrm{AR}$ alcançaram o máximo de $\mathrm{SS}$ no $3^{\circ}$ dia após a climatização e com relativa redução no 
$4^{\circ}$ dia, indicando que esses frutos haviam alcançado estádio de maturação ideal para a comercialização, e que ainda não estavam em senescência.

Nos frutos climatizados após 30 dias de refrigeração, verificaram-se os maiores teores de SS já no primeiro dia após a climatização, dada a intensa atividade metabólica nesses frutos, que implicou a diminuição do potencial de conservação. Após atingir os teores máximos de SS, com os diferentes tratamentos, observaram-se constantes reduções, ocasionadas pelo consumo de SS no metabolismo. Contudo, devido à precocidade na execução dos procedimentos de climatização dos frutos logo após a colheita, não foi possível constatar decréscimos nos teores de SS durante o período experimental.

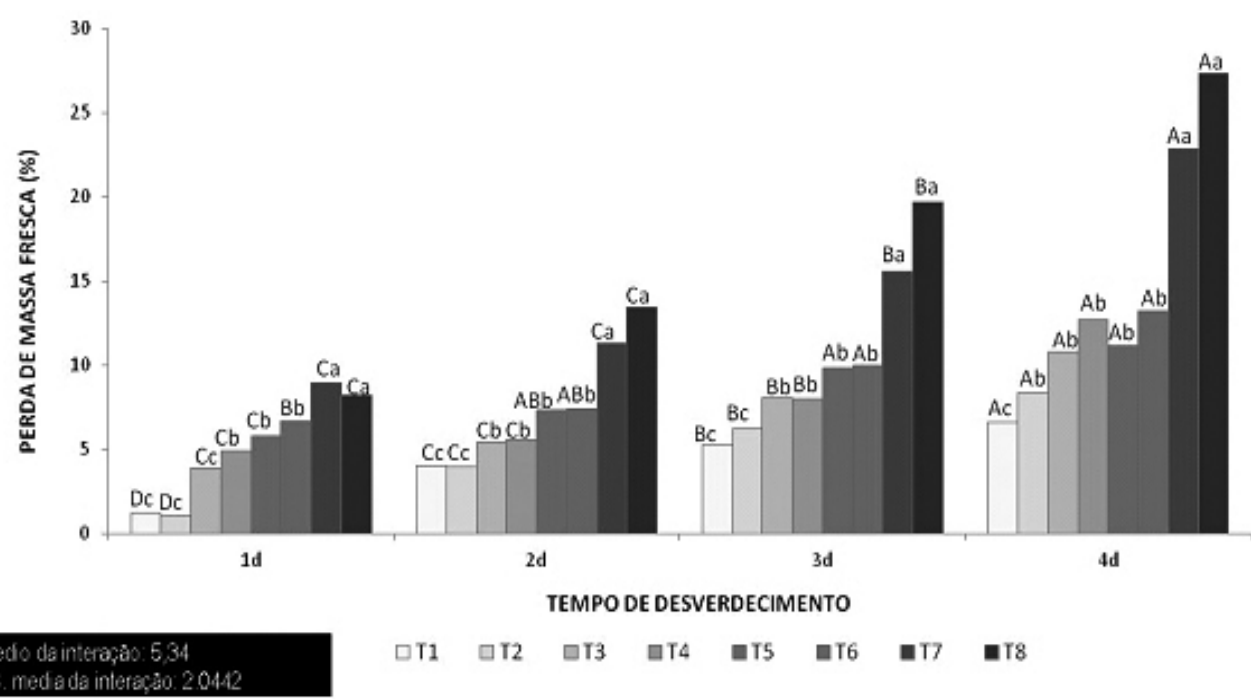

FIGURA 1 - Perda de massa fresca em bananas 'Prata-Anã' refrigeradas $\left(12 \pm 1^{\circ} \mathrm{C}, 93 \pm 2 \%\right.$ UR $)$ e climatizadas (T1-Abafamento na colheita; T2-Ethrel® na colheita; 3-Abafamento após 10 dias de AR; T4-Ethrel ${ }^{\circledR}$ após 10 dias de AR; T5-Abafamento após 20 dias de AR; T6-Ethrel ${ }^{\circledR}$ após 20 dias de AR; T7-Abafamento após 30 dias de AR; T8-Ethrel ${ }^{\circledR}$ após 30 dias de AR.). Médias seguidas de pelo menos uma letra comum, maiúscula nos dias de armazenamento e minúsculas entre os tratamentos, não diferem entre si, pelo teste de Tukey $(\mathrm{P}<0,05)$.

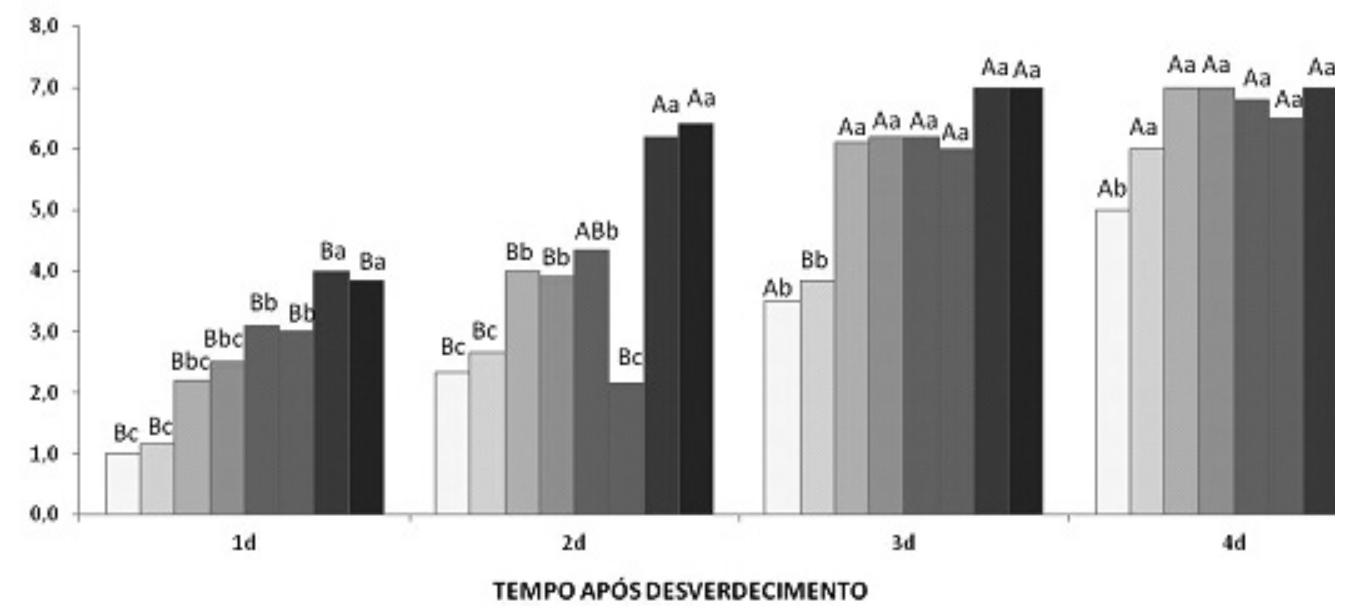

FIGURA 2 - Coloração em bananas 'Prata-Anã' refrigeradas $\left(12 \pm 1^{\circ} \mathrm{C}, 93 \pm 2 \%\right.$ UR) e climatizadas (T1-Abafamento na colheita; T2-Ethrel® na colheita; 3-Abafamento após 10 dias de AR; T4-Ethrel ${ }^{\circledR}$ após 10 dias de AR; T5-Abafamento após 20 dias de AR; T6-Ethrel ${ }^{\circledR}$ após 20 dias de AR; T7-Abafamento após 30 dias de AR, T8-Ethrelß após 30 dias de AR.). Médias seguidas de, pelo menos, uma letra comum, maiúscula nos dias de armazenamento e minúsculas entre os tratamentos, não diferem entre si, pelo teste de Tukey $(\mathrm{P}<0,05)$. 


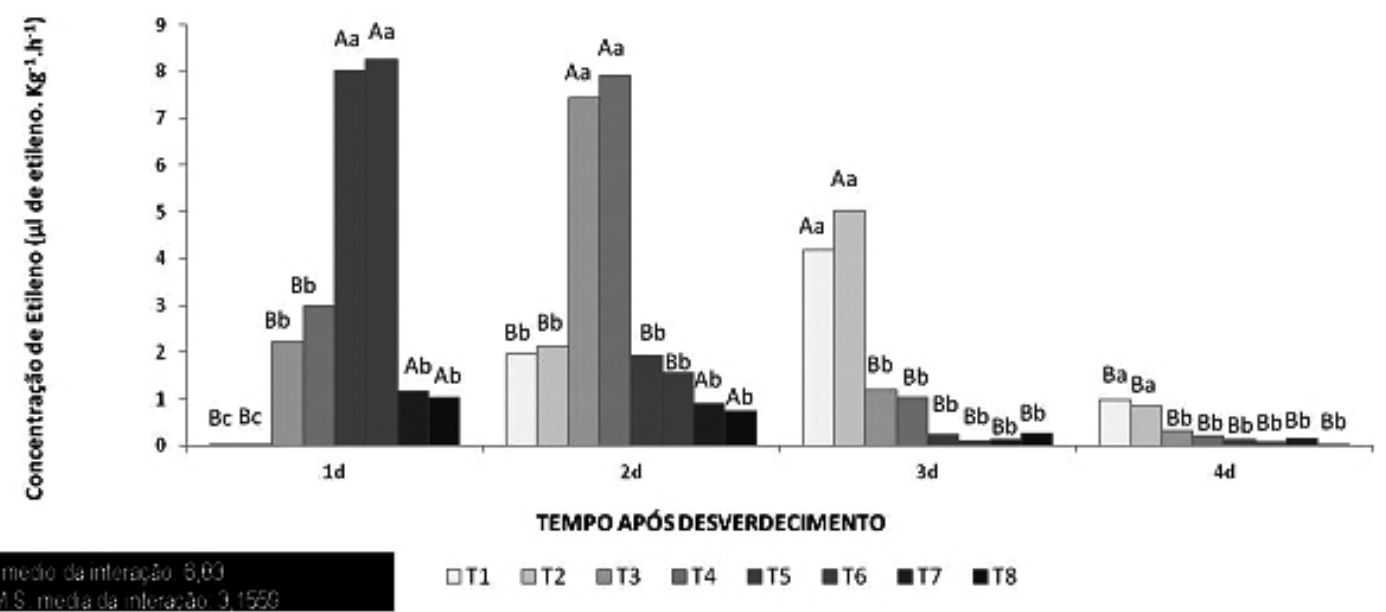

FIGURA 3A - Concentração de etileno em bananas 'Prata-Anã' refrigeradas $\left(12 \pm 1^{\circ} \mathrm{C}, 93 \pm 2 \%\right.$ UR) e climatizadas (T1-Abafamento na colheita; T2-Ethrel ${ }^{\circledR}$ na colheita; 3-Abafamento após 10 dias de AR;T4-Ethrel ${ }^{\circledR}$ após 10 dias de AR; T5-Abafamento após 20 dias de AR; T6-Ethrel ${ }^{\circledR}$ após 20 dias de AR; T7-Abafamento após 30 dias de AR;T8-Ethrel® após 30 dias de AR.). Médias seguidas de, pelo menos, uma letra comum, maiúscula nos dias de armazenamento e minúsculas entre os tratamentos, não diferem entre si, pelo teste de Tukey $(\mathrm{P}<0,05)$.

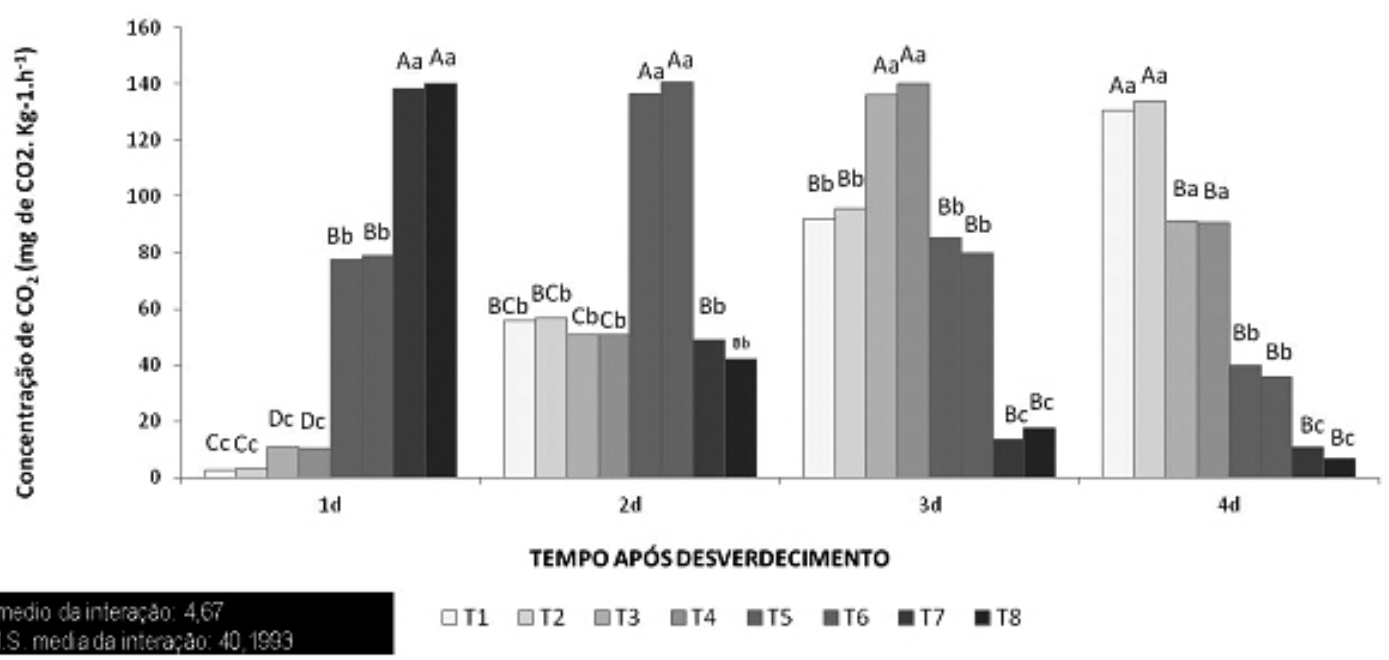

FIGURA 3B - Concentração de $\mathrm{CO}_{2}$ em bananas 'Prata-Anã' refrigeradas $\left(12 \pm 1^{\circ} \mathrm{C}, 93 \pm 2 \% \mathrm{UR}\right)$ e climatizadas (T1-Abafamento na colheita; T2-Ethrel ${ }^{\circledR}$ na colheita; 3-Abafamento após 10 dias de AR; T4-Ethrel ${ }^{\circledR}$ após 10 dias de AR; T5-Abafamento após 20 dias de AR; T6-Ethrel ${ }^{\circledR}$ após 20 dias de AR; T7-Abafamento após 30 dias de AR; T8-Ethrel ${ }^{\circledR}$ após 30 dias de AR.). Médias seguidas, de pelo menos, uma letra comum, maiúscula nos dias de armazenamento e minúsculas entre os tratamentos, não diferem entre si, pelo teste de Tukey $(\mathrm{P}<0,05)$. 


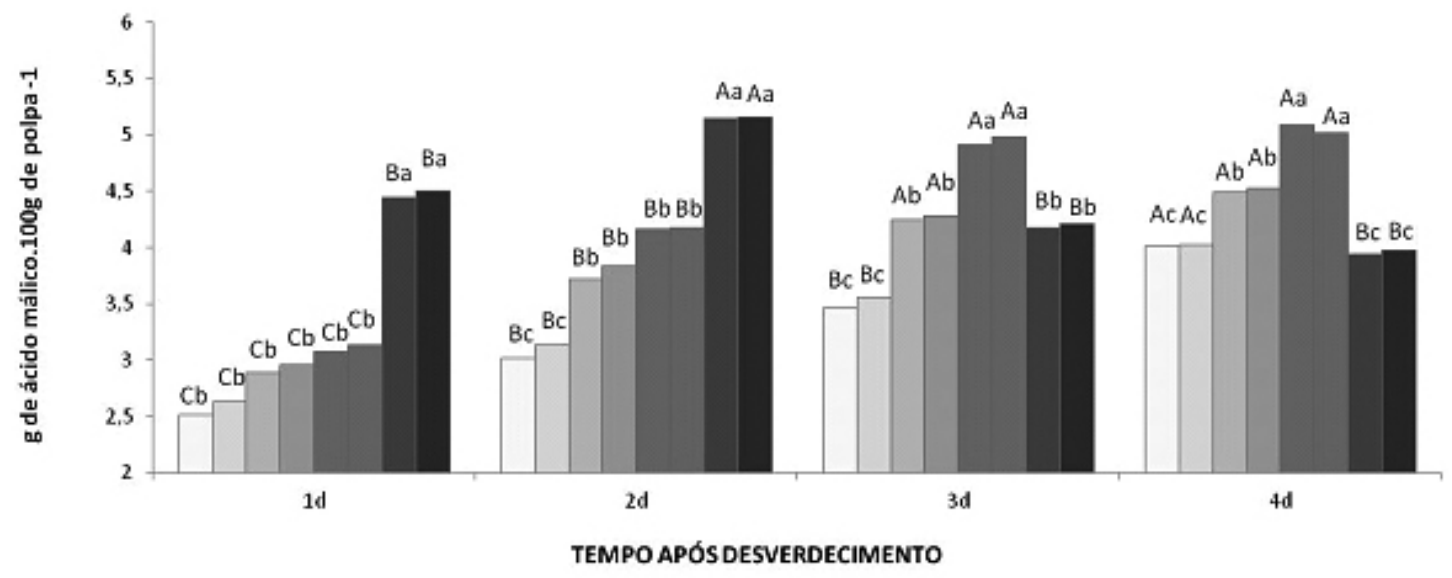

CW medio da interacto 2,56 D.M. medada interaca 0 3eg

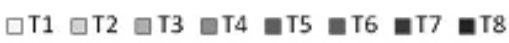

FIGURA 4 - Acidez titlável em bananas 'Prata-Anã' refrigeradas $\left(12 \pm 1{ }^{\circ} \mathrm{C}, 93 \pm 2 \%\right.$ UR) e climatizadas (T1-Abafamento na colheita, T2-Ethrel ${ }^{\circledR}$ na colheita;3-Abafamento após 10 dias de AR;T4Ethrel ${ }^{\circledR}$ após 10 dias de AR; T5-Abafamento após 20 dias de AR;T6-Ethrel ${ }^{\circledR}$ após 20 dias de AR; T7-Abafamento após 30 dias de AR; T8-Ethrel® após 30 dias de AR.). Médias seguidas de, pelo menos, uma letra comum, maiúscula nos dias de armazenamento e minúsculas entre os tratamentos, não diferem entre si, pelo teste de Tukey $(\mathrm{P}<0,05)$.
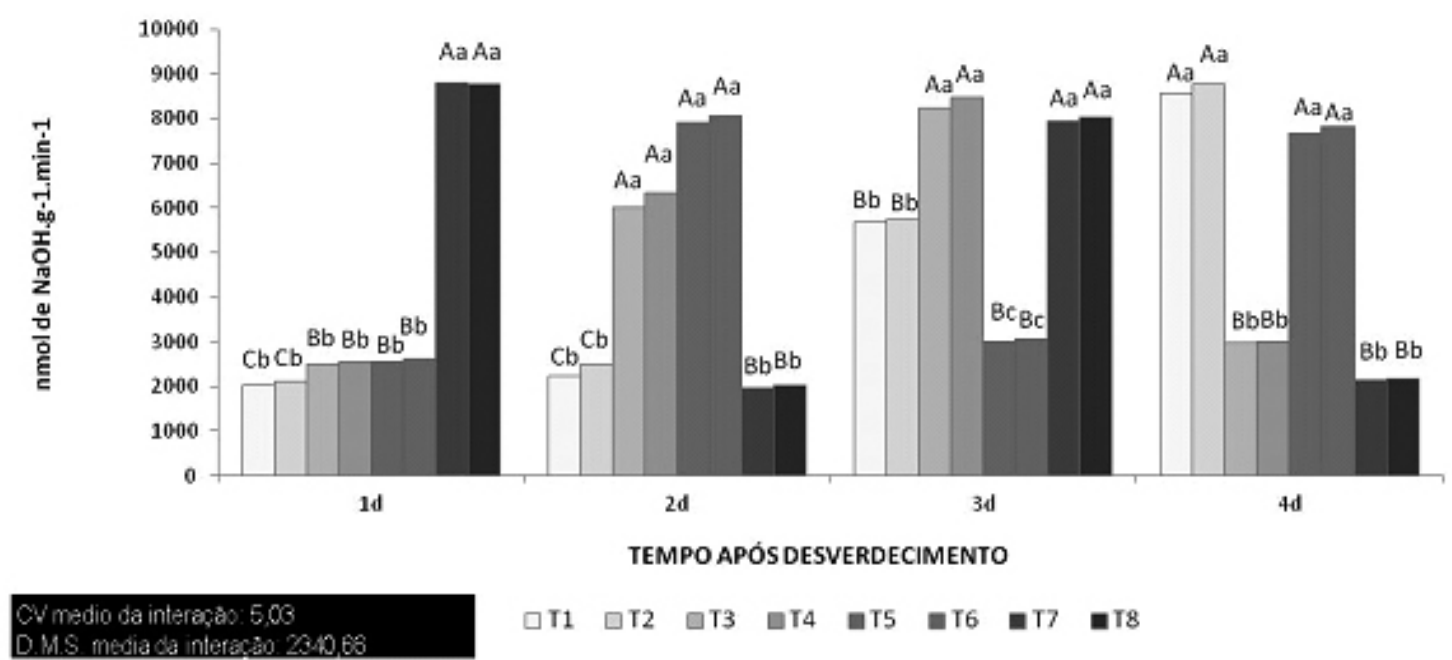

FIGURA 5A - Atividade da PME em bananas 'Prata-Anã' refrigeradas $\left(12 \pm 1^{\circ} \mathrm{C}, 93 \pm 2 \%\right.$ UR $)$ e climatizadas (T1-Abafamento na colheita; T2-Ethrel ${ }^{\circledR}$ na colheita; 3-Abafamento após 10 dias de AR; T4-Ethrel ${ }^{\circledR}$ após 10 dias de AR; T5-Abafamento após 20 dias de AR; T6-Ethrel ${ }^{\circledR}$ após 20 dias de AR;T7-Abafamento após 30 dias de AR; T8-Ethrel ${ }^{\circledR}$ após 30 dias de AR.). Médias seguidas de , pelo menos, uma letra comum, maiúscula nos dias de armazenamento e minúsculas entre os tratamentos, não diferem entre si, pelo teste de Tukey $(\mathrm{P}<0,05)$. 


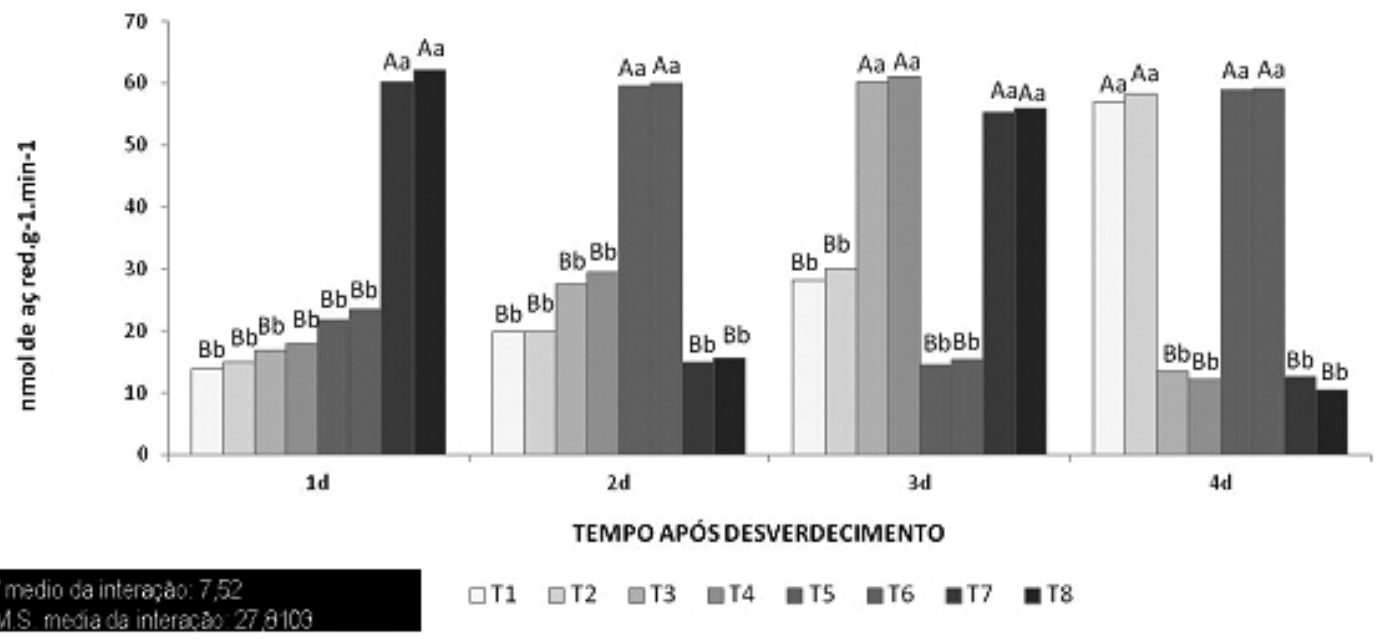

FIGURA 5B - Atividade da PG em bananas 'Prata-Anã' refrigeradas $\left(12 \pm 1^{\circ} \mathrm{C}, 93 \pm 2 \% \mathrm{UR}\right)$ e climatizadas (T1-Abafamento na colheita; T2-Ethrel ${ }^{\circledR}$ na colheita; 3-Abafamento após 10 dias de AR;T4 Ethrel ${ }^{\circledR}$ após 10 dias de AR; T5-Abafamento após 20 dias de AR; T6-Ethrel ${ }^{\circledR}$ após 20 dias de AR; T7-Abafamento após 30 dias de AR;T8-Ethrel ${ }^{\circledR}$ após 30 dias de AR.). Médias seguidas de, pelo menos uma letra comum, maiúscula nos dias de armazenamento e minúsculas entre

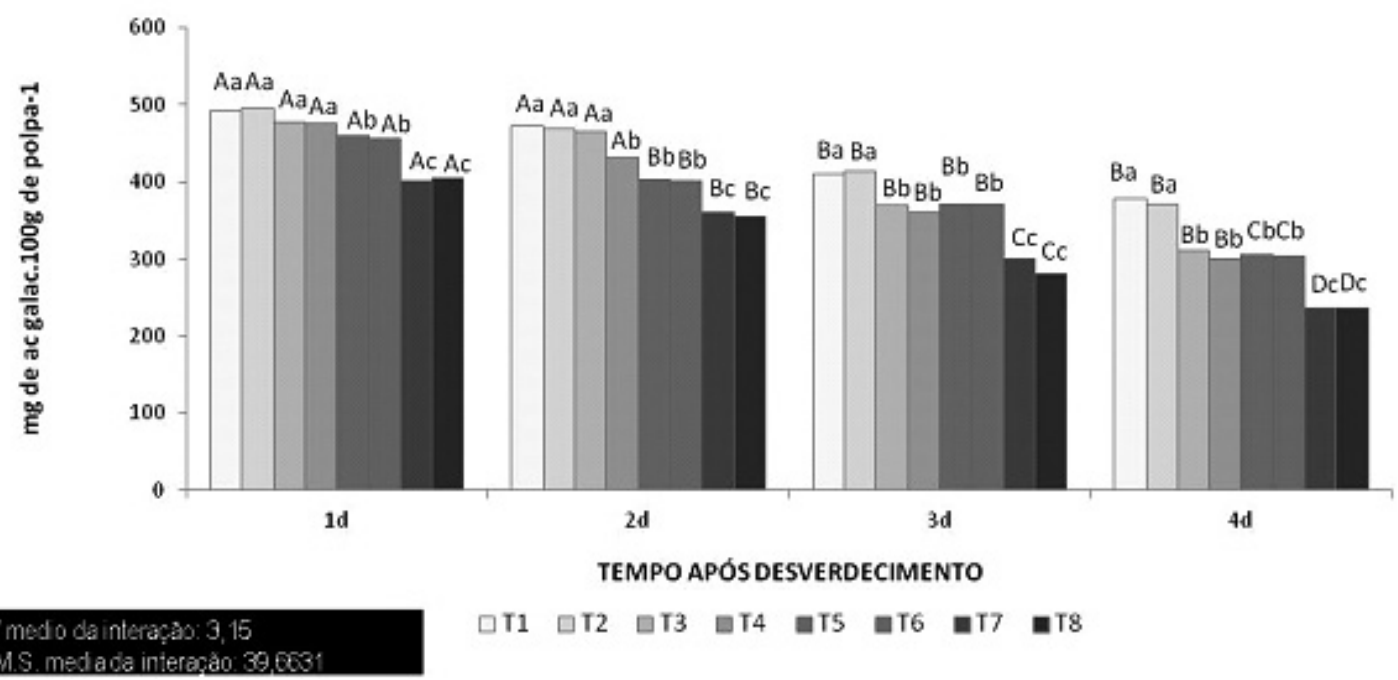

FIGURA 6A - Pectina total em bananas 'Prata-Anã' refrigeradas $\left(12 \pm 1^{\circ} \mathrm{C}, 93 \pm 2 \%\right.$ UR $)$ e climatizadas (T1-Abafamento na colheita; T2-Ethrel ${ }^{\circledR}$ na colheita; 3-Abafamento após 10 dias de AR; T4-Ethrel ${ }^{\circledR}$ após 10 dias de AR; T5-Abafamento após 20 dias de AR; T6-Ethrel ${ }^{\circledR}$ após 20 dias de AR; T7-Abafamento após 30 dias de AR; T8-Ethrel® após 30 dias de AR.). Médias seguidas de, pelo menos,uma letra comum, maiúscula nos dias de armazenamento e minúsculas entre os tratamentos, não diferem entre si, pelo teste de Tukey $(\mathrm{P}<0,05)$. 


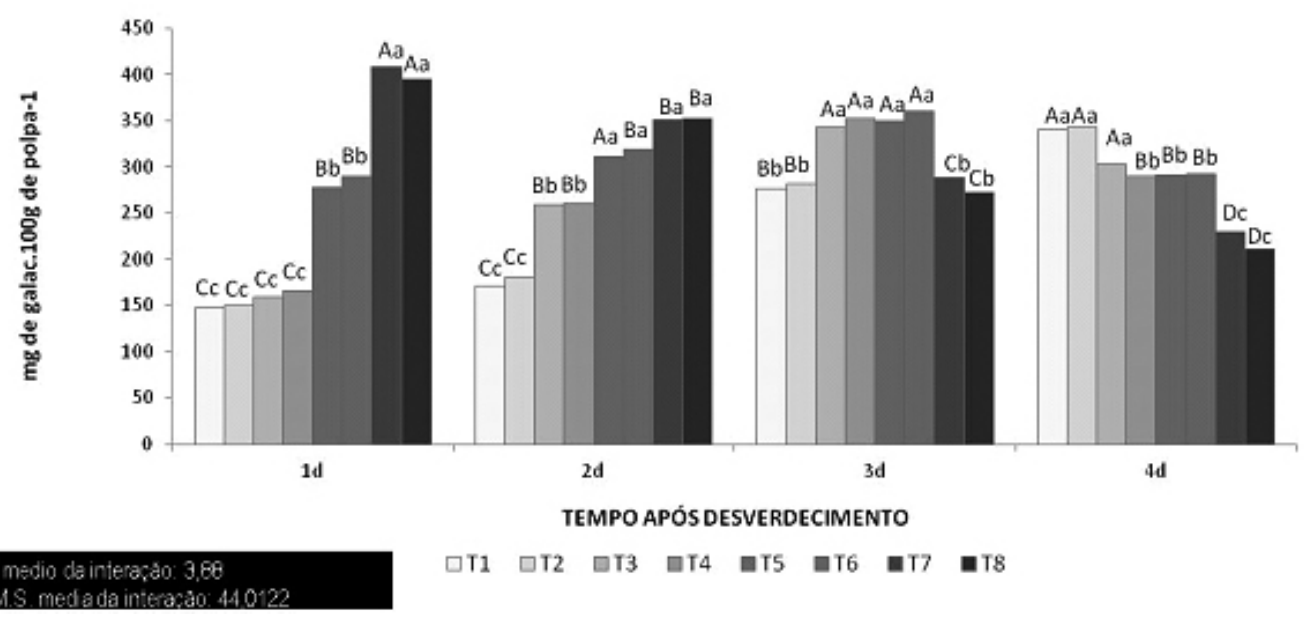

FIGURA 6B - Pectina solúvel em bananas 'Prata-Anã' refrigeradas $\left(12 \pm 1^{\circ} \mathrm{C}, 93 \pm 2 \%\right.$ UR) e climatizadas (T1-Abafamento na colheita; T2-Ethrel ${ }^{\circledR}$ na colheita; 3-Abafamento após 10 dias de AR; T4-Ethrel ${ }^{\circledR}$ após 10 dias de AR; T5-Abafamento após 20 dias de AR; T6-Ethrel ${ }^{\circledR}$ após 20 dias de AR; T7-Abafamento após 30 dias de AR;T8-Ethrel ${ }^{\circledR}$ após 30 dias de AR.). Médias seguidas de, pelo menos, uma letra comum, maiúscula nos dias de armazenamento e minúsculas entre os tratamentos, não diferem entre si, pelo teste de Tukey $(\mathrm{P}<0,05)$.

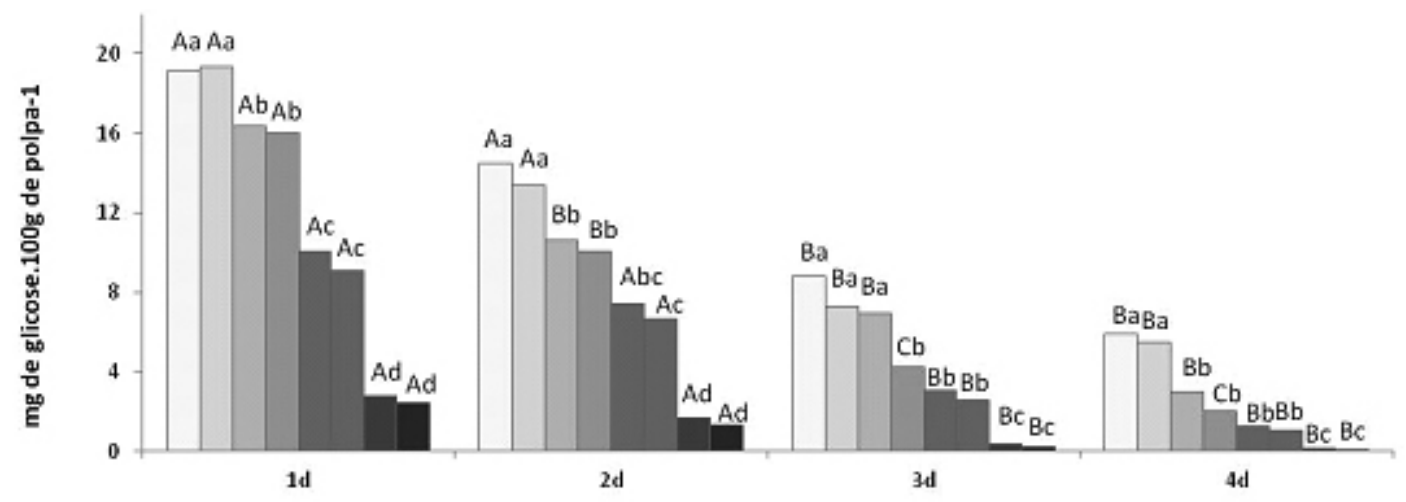

TEMPO APÓS DESVERDECIMENTO

FIGURA 7 - Amido em bananas 'Prata-Anã' refrigeradas $\left(12 \pm 1^{\circ} \mathrm{C}, 93 \pm 2 \%\right.$ UR) e climatizadas (T1-Abafamento na colheita; T2-Ethrel ${ }^{\circledR}$ na colheita;3-Abafamento após 10 dias de AR; T4-Ethrel ${ }^{\circledR}$ após 10 dias de AR; T5-Abafamento após 20 dias de AR; T6-Ethrel ${ }^{\circledR}$ após 20 dias de AR; T7-Abafamento após 30 dias de AR; T8-Ethrel ${ }^{\circledR}$ após 30 dias de AR.). Médias seguidas de, pelo menos, uma letra comum, maiúscula nos dias de armazenamento e minúsculas entre os tratamentos, não diferem entre si pelo teste de Tukey $(\mathrm{P}<0,05)$. 


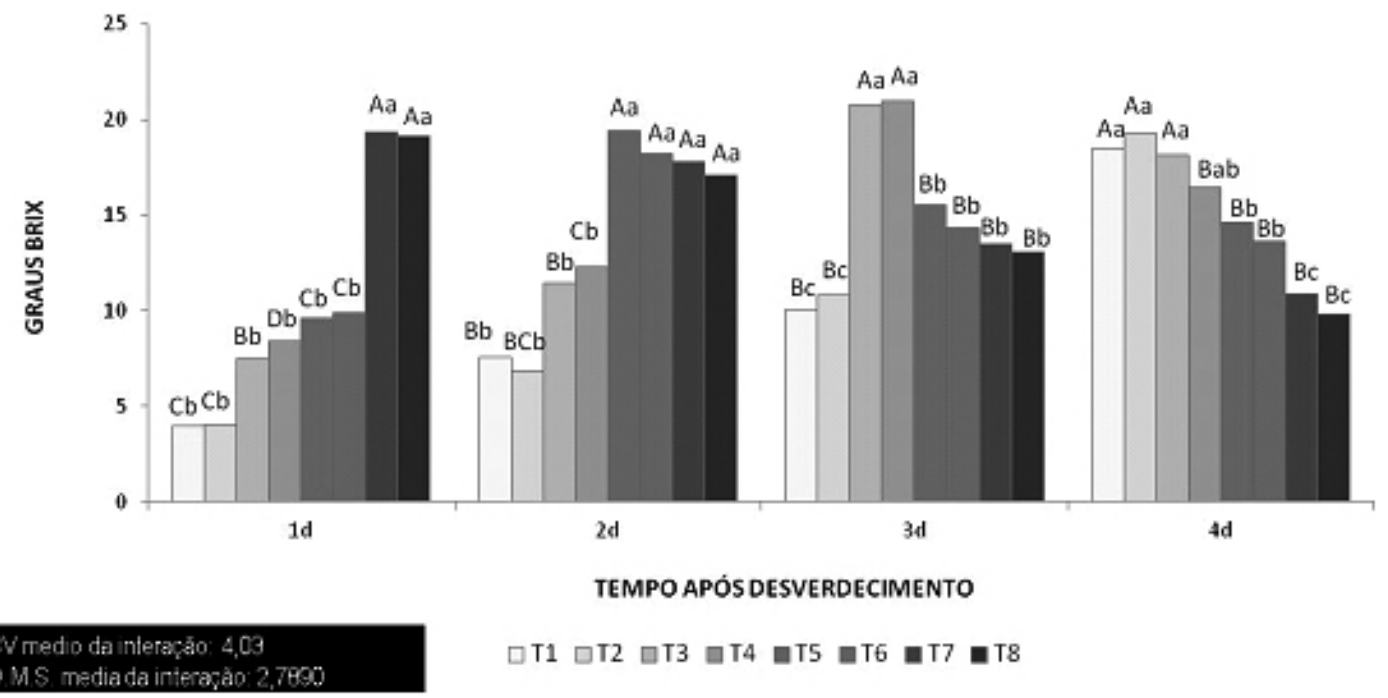

FIGURA 8 - Sólidos solúveis em bananas 'Prata-Anã' refrigeradas $\left(12 \pm 1^{\circ} \mathrm{C}, 93 \pm 2 \% \mathrm{UR}\right)$ e climatizadas (T1-Abafamento na colheita; T2-Ethrel ${ }^{\circledR}$ na colheita; 3-Abafamento após 10 dias de AR; T4-Ethrel ${ }^{\circledR}$ após 10 dias de AR; T5-Abafamento após 20 dias de AR; T6-Ethrel ${ }^{\circledR}$ após 20 dias de AR;T7-Abafamento após 30 dias de AR;T8-Ethrel ${ }^{\circledR}$ após 30 dias de AR.). Médias seguidas de, pelo menos, uma letra comum, maiúscula nos dias de armazenamento e minúsculas entre os tratamentos, não diferem entre si, pelo teste de Tukey $(\mathrm{P}<0,05)$.

\section{CONCLUSÕES}

1- Pelos resultados obtidos, não é possível atestar, conclusivamente, qual dos dois métodos de climatização executados (Ethrel ${ }^{\circledR}$ e abafamento), melhor promove o amadurecimento das bananas com a adequada preservação da qualidade sensorial dos frutos.

2- Constata-se que quanto maior o período de $\mathrm{AR}$, menor é o período entre a climatização e o início do processo de senescência dos frutos.

3- Recomenda-se o período de até 20 dias de AR, nas condições de temperatura e umidade realtiva aqui testadas, para que a climatização das bananas fosse realizada de maneira segura, ou seja, induzindo o amadurecimento sem, contudo, diminuir drasticamente, a qualidade sensorial e a vida útil dos frutos. Nessas condições, é possível manter a qualidade sensorial das bananas por até 3 dias após a climatização e a retirada dos frutos do AR.

\section{REFERÊNCIAS}

ALVES, A. B..; LIMA, K. N.; VIEIRA, B. de A. H. Cultivo da banana em Roraima. Boa Vista: Embrapa Roraima, 2007. 90f. (Documentos 01).

BISOGNIN, D. A.; BENEDETTI, M.; SEGATTO, F. B.; COSTA, L. C.; RITTER, C. E. L.; BRACKMANN, A. Efeito do $\mathrm{CO}_{2}$ e etileno no período de dormência de minitubérculos de batata cv. Macaca. Horticultura Brasileira, Vitória da Conquista, v. 25, n. 2, p. 138-142, 2007.

BITTER, T.; MUIR, H. M. A modified uronic acid carbazole reaction. Analytical Chemistry, New York, v. 34, p. 330-334, 1962.

BOTREL, N., SILVA, O.F., BITTENCOURT, A.M. Procedimentos pós-colheita. In: CAMPOS, R. P.; VALENTE, J. P.; PEREIRA, W. E. Conservação pós-colheita de banana cv. Nanicão climatizada e comercializada em Cuiabá - MT e região. Revista Brasileira de Fruticultura, Jaboticabal, v. 25, n. 1, p. 172-174, 2003. 
CEAGESP: PBMH e PIF - PROGRAMA BRASILEIRO PARA A MODERNIZAÇÃO DA HORTICULTURA e PRODUÇÃO INTEGRADA DE FRUTAS. Normas de Classificação de Banana. São Paulo: CEAGESP, 2006. (Documento, 29).

FAO - Food and Agriculture Organization of the United Nations, 2009. Disponível em: $<$ http://faostat.fao.org>. Acesso em: 07 mar. 2011.

IAL - Instituto Adolfo Lutz. Métodos físico-químicos para análise de alimentos. São Paulo, 2008. p. 1020. versão eletrônica.

JEN, J.J.; ROBINSON, M.L.P.. Pectolytic enzymes in sweet bell peppers (Capsicum annum L.). Journal of Food Science, Chicago, v. 49, n. 4, p. 1085-1087, 1984

KADER, A.A. Postharvest biology and technology: an overview. In: KADER, A.A. (Ed.). Postharvest technology of horticultural crops. $3^{\text {rd }}$ ed. Berkeley: University of California, 2002. p. 39-47.

LICHTEMBERG, L. A.; MALBURG, J. L., HINZ, R. H. Suscetibilidade varietal de frutos de bananeira ao frio. Revista Brasileira Fruticultura, Jaboticabal, v. 23, n. 3, p. 985-992, 2001.

MANOEL, L. Qualidade e conservação de banana nanica irradiada, climatizada e refrigerada. 2008. 102 f. Tese (Doutorado) - Faculdade de Ciências Agronômicas, Universidade Estadual Paulista, Botucatu, 2008.

MARTINS, R. N.; DIAS, M. S. C.; VILLAS BOAS, E. V. de B.; SANTOS, L. O. Armazenamento refrigerado de banana 'Prata Anã' proveniente de cachos com 16, 18 e 20 semanas. Ciência e Agrotecnologia, Lavras, v. 31, n. 5, 2007.

MATSUURA, F. C. A. U.; COSTA, J. I. P. da; FOLEGATTI, M. I. da S. Marketing de banana: preferências do consumidor quanto aos atributos de qualidade dos frutos. Revista Brasileira de Fruticultura, Jaboticabal, v. 26, n. 1, p. 48-52, 2004.

McCREADY, R. M.; McCOOMB, E. A. Extraction and determination of total pectic materials in fruits. Analytical Chemistry, Washington, v. 42, n. 12, p. 1586-1588, 1952.

MEDINA, V. M. Indução da banana 'Terra'com Etefon. Cruz das Almas: EMBRAPA, 2004. (Circu- lar Técnica, 71). Disponível em: $\leq$ http://www.cnpmf. embrapa.br/publicacoes $>$. Acesso em: 13 nov. 2009.

MELO, A. A. M.; VILAS BOAS, E. V. de B. Redução do amaciamento de banana 'Maçã' minimamente processada pelo uso de tratamentos químicos. Ciência e Agrotecnologia, Lavras, v. 31, n. 3, p. 821-828, 2007.

MOREIRA, N. X.; NEVES, L. C.; BENEDETTE, R. M.; XAVIER, V.; VIEITES, R. L. Estudo das Relações Comerciais na Feira do Produtor em Boa Vista/ RR e na Feira da Banana em Manaus/AM., Revista Mens Agitat, Boa Vista, v. 2, n. 1, p. 59-66, 2007.

NEVES, L. C.; BENEDETTE, R. M.; SILVA, V. X.; PRILL, M. A. de S.; ROBERTO, S. R.; VIEITES, R. L. Qualidade pós-colheita de mangas, não-refrigeradas, e submetidas ao controle da ação do etileno. Revista Brasileira de Fruticultura, Jaboticabal, v. 30, n. 1, p. 94-100, 2008.

NEVES, L. C.; BENEDETTE; R.M; SILVA, V.X da; VIEITES, R.L.; ROBERTO, S.R. Utilização de diferentes embalagens plásticas para a conservação de produto minimamente processado de mangas 'Tommy Atkins'. Revista Brasileira de Fruticultura, Jaboticabal, n. 3, v. 31, p. 856-864, 2009.

NEVES, L. C.; PRILL, M. A de S., BENEDETTE, R. M. SILVA, V. X. (Org.). Manual pós-colheita da fruticultura brasileira. Londrina: EDUEL, 2009. p.387-397.

NOGUEIRA, D. H.; PEREIRA, W. E.; SILVA, S. de M. e ARAUJO, R. da C. Mudanças fisiológicas e químicas em bananas 'Nanica' e 'Pacovan' tratadas com carbureto de cálcio. Revista Brasileira Fruticultura, Jaboticabal, v.29, n. 3, p. 460-464, 2007.

PRESSEY, R.; AVANTS, J.K.Separation and characterization of exopolygalacturonase and endopolygalacturonase from peaches. Plant Physiology, Baltimore, v. 52, n. 3, p. 252-256, 1973.

ROCHA, A. Uso de permanganato de potássio na conservação pós-colheita de banana 'Prata'. 2005. 82 f. Dissertação (Mestrado) - Universidade Federal de Viçosa, Viçosa, 2005.

SAlES, A. N. de; BOTREL, N. e COELHO, A. H. R. Aplicação de 1-metilciclopropeno em banana 
'Prata-Anã' e seu efeito sobre a substâncias pécticas e enzimas pectinolíticas. Ciência e Agrotecnologia, Lavras, v. 28, n. 3, p. 479-487, 2004.

SILVA, C. de S.; LIMA, L. C.; SANTOS, H. S; CAMILI, E. C.; VIEIRA, C. R. I. Y.; MARTIN, C. da S.; VIEITES, R. L. Amadurecimento da banana-prata climatizada em diferentes dias após a colheita.
Ciência e Agrotecnologia, Lavras, v. 30, n. 1, 2006.

SOLOESTE IND. COM. EXPORTAÇÃO LTDA. PRODUTOS ALWAYS FRESH .Disponível em: $<$ http://www.soloeste.com $>$. Acesso em: 09 nov. 2009. 